Monica W Nortvedt,

Senter for kunnskapsbasert

praksis, Høgskolen i Bergen og

Gro Jamtvedt,

Nasjonalt kunnskapssenter

for helsetjenesten

\section{Kunnskapsbasert praksis handler om å bruke eksis- terende forskning, ikke å forske selv.}

\section{www.sykepleien.no}

Les mer og finn litteraturhenvisninger på www.sykepleien.no

\section{Søkeord:}

Kunnskapsbasert sykepleie Kunnskapsbasert praksis Forskning

\title{
Engasjerer og provoserer
}

\section{En kliniker som sammen med god forskningsbasert kunnskap bruker sin kliniske erfaring og aktivt innhenter og møter pasients verdier og preferanser, arbeider kunnskapsbasert. Dette støttes av pasien- ter og klinikere, men provoserer noen akademikere $\mathrm{i}$ helsefagene.}

Pasienter og brukere av helsetjenester ønsker å bli mottatt med respekt, og de forventer å få pleie og behandling av god kvalitet. De forventer videre at unødvendige undersøkelser og komplikasjoner, for eksempel infeksjoner, unngås. Helsepersonell ønsker å gi pasientene den beste pleien og behandlingen, og det er derfor vanskelig å forstå at studier viser at 30-40 prosent av pasientene ikke får behandling i henhold til vitenskapelig dokumentasjon og at 20-25 prosent av all behandling er unødvendig, eller skadelig $(1,2)$. Det er beregnet at cirka 2000 norske pasienter dør årlig, og at 15.000 pasienter får varige skader av feilbehandling (3). Noe av dette skyldes utilsiktede hendelser, og noe skyldes at vi handler uten å være oppdatert. Undersøkelser gjennomført både i Helse Vest og Helse Sør-Øst bekrefter at det er store forbedringspotensialer også i Norge. Sykepleiere er den største profesjonen i helsetjenesten. Som profesjonsutøvere påvirker vi pasientresultat og system, og vi bør bruke dette bevisst til pasientenes beste. Det er derfor av vesentlig betydning at sykepleiere har den nødvendige kompetansen til å utøve god sykepleie innbefattet evne til å ta velinformerte beslutninger. Dette er kjernen i kunnskapsbasert praksis.

\section{I vekst}

Konseptet kunnskapsbasert praksis har hatt en vekst både internasjonalt, og i Norge. I utgangspunktet ble dette initiert innen medisin da en så at svært lite av medisinsk praksis var tuftet på pålitelig kunnskap. Både fysioterapeuter $(4,5)$, ergoterapeuter (6) og sykepleiere $(7,8)$ har imidlertid bidratt til en mer helsefaglig vinkling av konseptet. I dag snakker man også om kunnskapsbasert utdanning, kriminalomsorg, sosialfag, ingeniørfag, fredsarbeid og så videre. Nasjonalt kunnskapssenter for helsetjenesten og Senter for kunnskapsbasert praksis ved Høgskolen i Bergen har sentrale nasjonale roller i å fremme kunnskapsbasert praksis og forvaltning, blant annet ved å produsere kunnskapsoppsummeringer, etablere helsebiblioteket og utvikle utdanninger på ulike nivåer, inkludert masternivå. I tillegg jobber alle de regionale helseforetakene aktivt for å fremme kunnskapsbasert praksis og både Helse-Vest og Helse Sør-Øst har dette som strategisk satsingsområde.
Norsk sykepleieforbund (NSF), Norsk Fysioterapeutforbund, Ergoterapeutforbundet og Radiografforbundet, med sine tilhørende fagtidsskrift, har markert seg aktivt innen kunnskapsbasert praksis via temanummer, prosjekter, konferanser og kurs. I 2007 ble vi inviterte av NSF til å skrive en arbeidsbok som skulle være en hjelp for sykepleiere til å komme i gang med å arbeide kunnskapsbasert. Da boken ble publisert høsten 2007 ble den distribuert gratis til 15000 sykepleiere, og den ble svært godt mottatt. I ettertid er den trykket i nytt opplag på 5000 eksemplarer, og boken er basis for nettkurset www.kunnskapsbasertpraksis.no som ligger gratis på internett. Ressursene som er utviklet brukes i praksis, og i utdanning av helsepersonell, både på bachelor- og mastergradsnivå.

\section{Kritikken}

Kritikk mot kunnskapsbasert praksis er løftet fram av flere i Norge (9-12) og noen kritikere har gått så langt som til å hevde at kunnskapsbasert praksis passer best for tvangsnevrotikere, personer som underkaster seg og for dem som er opptatt av en instrumentell praksis (13-15). 
Figur 1: Trinnene i kunnskapsbasert praksis

\section{Refleksjon}

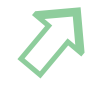

VI. Evaluere<smiles>CC1C2CC3CC(C2)CC1C3</smiles>

\section{Anvende}

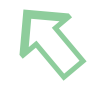

\section{Kritisk vurdering}

(19). Hun ønsket med denne boken å øke mulighetene for at vitenskapelig kunnskap kan brukes på en fornuftig måte til å fremme praksis. I boken skiller Kirkevold mellom vurderingskompetanse og anvendelseskompetanse. Med vurderingskompetanse menes å kunne lese og forstå vitenskapelig kunnskap, kritisk vurdere denne og foreta en bedømmelse av kunnskapen. Med anvendelseskunnskap menes å kunne velge relevant kunnskap i forhold til foreliggende situasjon, tolke situasjonen opp mot teori og utforme handlinger og tilnærmingsmåter med utgangspunkt i vitenskapelig kunnskap (19).

\section{Arbeidsprosessen}

Vi presenterer prosessen med å arbeide kunnskapsbasert som en sirkel kunnskap. Men vi er også opptatt av å utvikle og formidle ulike modeller for anvendelse i praksis. Anvendelseskompetanse må imidlertid primært læres i de fagspesifikke utdanningene, samt i praksis.

Modellen vår inneholder ulike kunnskapskilder; forskningsbasert kunnskap, erfaringsbasert kunnskap og brukerkunnskap, samt kontekst (figur 2). Den presenteres som en statisk modell der kildene synes å ha like stor tyngde eller betydning. Som vi påpeker i boken, vil imidlertid ulike pasientmøter føre til at kildenes vekting varierer. Heggen og Engebretsen (15) har, via det de kaller dekonstruert lesning, funnet ut at vi har laget et hierarki av disse kildene med en rangering der forskningsbasert kunnskap rangeres øverst, og brukerkunnskap lavest. Det er mulig at vi har et unyansert språk i boken, men denne rangeringen står vi faktisk ikke for. Det vil alltid, i konkrete situasjoner være noen kunnskapskilder som veier tyngre enn andre, uten at man på generelt grunnlag kan si at en type kunnskap er mer verdifull enn en annen. Vi vil her gi noen eksempler på ulike situasjoner og måter å anvende kunnskapen på.

\section{Konkrete situasjoner}

Kunnskapsbasert klinisk praksis handler om å håndtere forskningsbasert kunnskap i møter med individuelle pasienter og brukere. Den samme forskningsbaserte kunnskapen kan føre til ulike beslutninger i ulike kliniske situasjoner. Forskning viser for eksempel at pasienter bør mobiliseres raskt etter et hjerteinfarkt, i motsetning til tidligere der man rådet pasientene til å holde seg mer i ro. En erfaren sykepleier kan likevel vurdere at pasienten ikke skal mobiliseres den aktuelle dagen. I denne situasjonen er det den kliniske erfaringen og ekspertisen som har avgjørende betydning for utfallet. Andre ganger kan pasienten selv, til tross for å være informert om viktigheten av tidlig mobilisering, velge å holde sengen. I denne situasjonen er det pasientens preferanser som blir vektlagt. Så lenge beslutningene er velinformerte vil vi si at det er kunnskapsbasert praksis. Forskningsbasert kunnskap alene skal ikke diktere praksis, men informere denne. I disse eksemplene er forskningsbasert kunnskap en basis, men praksis kan og bør variere på grunn av pasientens situasjon. Generelt å oppmuntre pasienten til å holde seg mest mulig $\mathrm{i}$ ro etter et hjerteinfarkt vil ikke være kunnskapsbasert praksis.

\section{Beslutninger på generelt grunnlag}

Når man skal utvikle kunnskapsbaserte prosedyrer, nasjonale retningslinjer eller bidra til kunnskapsbasert helsepolitikk kan man involvere kliniske eksperter og representanter for pasienter i arbeidet. Disse vil bidra med erfaringsbasert kunnskap og brukerkunnskap. Hvorvidt denne kunnskapen vil ha betydning for anbefalingene som formuleres vil variere, men det vil alltid være et samspill mellom kvaliteten på forskningen, klinisk erfaring, overførbarhet, kostnader, mulige bivirkninger og pasienterfaringer. Det samme gjelder i situasjoner hvor man tilpasser internasjonale retningslinjer til nasjonale eller lokale forhold, og dersom helsedirektøren for eksempel 


\section{Forskningsbasert kunnskap alene skal ikke diktere praksis, men informere denne.}

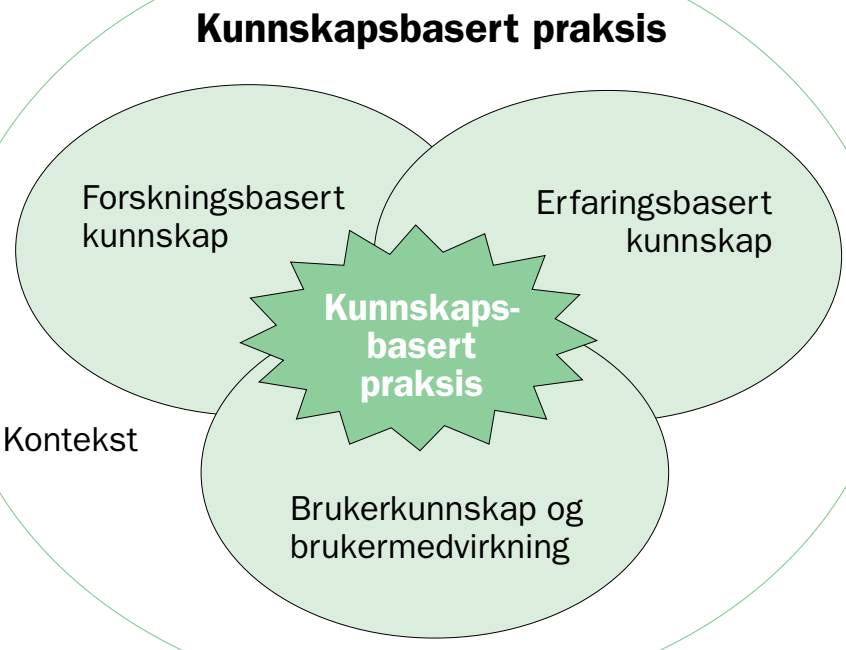

skal iverksette et tiltak for å redusere røyking i befolkningen. Ved viktige prioriteringer i helsetjenesten, som for eksempel ved innføring av ny og kostbar teknologi i sykehus, har Norge etablert et nasjonalt råd for kvalitet og prioriteringer som skal hjelpe helsetjenesten til å ta slike kollektive beslutninger, www.kvalitetogprioritering.no I rådet sitter både ledere, eksperter og pasienter.

\section{Forskningsbasert kunnskap}

Kunnskapsbasert praksis handler om å bruke eksisterende forskning, ikke å forske selv. Men det er likevel viktig å forske på kunnskapsbasert praksis som konsept, og på problemstillinger knyttet til hver av kunnskapskildene i modellen. Det finnes i dag mye forskningsbasert kunnskap om hvordan erfaring utvikles i ulike helsefag. Likeledes er forskning om betydningen av kontekst for praksis viktig, - og forskning om hvordan brukerkunnskap og brukermedvirkning kan fremmes. På den måten kan forskningsbasert kunnskap om klinisk erfaring og brukermedvirkning bidra til bedre forståelse og anvendelse av kunnskapsbasert praksis.

Forskere innenfor kunnskapsbasert praksis er spesielt opptatt av å generere kunnskap om anvendelse og evaluering av praksis (trinn $5 \mathrm{og}$ 6) (figur 1). Innen flere helsefag er barrierer og motivasjonsfaktorer for kunnskapsbasert praksis etter hvert godt beskrevet (20-23). Neste steg er at man utvikler og evaluerer ulike måter å fremme kunnskapsbasert praksis i medisin og helsefagene, for eksempel ved å evaluere effekten av kurs og opplæring, implementering av retningslinjer med mer (24-27). EPOC-gruppen i Cochrane Collaboration oppsummerer slike studier, www.epoc.cochrane.org. Stipendiater og Mastergradsstudenter ved $\mathrm{HiB}$ vil spesielt prioritere slike spørsmål i sine prosjektoppgaver.

Helsearbeidere har en samlet kompetanse som omfatter holdninger, ferdigheter og kunnskap innen mange fagområder. Som nyansatt eller student i for eksempel arbeid med ungdom og seksualitet, vil det være naturlig å stille seg spørsmål av generell art slik som; «Hvilke kjønnssykdommer finnes blant ungdom $\mathrm{i}$ Norge?», eller «Hva er klamydia?». Slike spørsmål kaller vi bakgrunnsspørsmål og de gir generell kunnskap om en tilstand eller sykdom (7-8). Eksempler på fagfelt som bidrar til bakgrunnskunnskap hos en sykepleiestudent inkluderer sykepleieteori, etikk, psykologi, fysiologi, sykdomslære, samfunnskunnskap og administrasjon. Etter hvert som man får mer erfaring, vil bakgrunnskunnskapen være integrert og man vil være bedre i stand til å stille fokuserte kliniske spørsmål som kan formuleres slik: «Er gratis utdeling av kondomer et effektivt tiltak for å forebygge klamydia blant ungdom?» eller «Hvorfor er det så vanskelig å få ungdommer til å bruke kondom?». Dette kaller vi forgrunnsspørsmål. Når man setter seg inn i et nytt fagfelt, eller er student, vil man ha flere bakgrunnsspørsmål enn forgrunnsspørsmål. De første trinnene i kunnskapsbasert praksis hjelper oss til å få svar på forgrunnsspørsmål, og det er spesielt i anvendelsen (i trinn fem), at bakgrunnskunnskapen er essensiell. Både kvalitative og kvantitative forskningsmetoder kan bidra til forgrunns- og bakgrunnskunnskap (28). Å syntetisere bakgrunns og forgrunnskunnskap, erfaring og brukermedvirkning i den gitte situasjonen krever anvendelseskompetanse. Dette er å sette modellen for kunnskapsbasert praksis sammen.

\section{Randomiserte kontrollerte studier (RCT)}

Alle forskningsmetodiske tilnærminger kan i prinsippet bidra i kunnskapsbasert praksis, det handler om å finne forskningen som besvarer det kliniske spørsmålet. Ulike typer spørsmål belyses av ulike forskningsmetoder. Innen kunnskapsbasert praksis har imidlertid spørsmål om effekt av tiltak en sentral plass. Dette er kanskje en av helsetjenestens viktigste spørsmål. Råd og virkemidler fra helsepersonell griper inn i menneskers liv for å påvirke et sykdomsforløp eller forebygge problemer, og vi bør unngå å gjøre mer skade enn gagn. Vi har dessverre flere eksempler på at velmenende tiltak faktisk kan skade, jamfør råd om å la spedbarn sove på magen og utstrakt bruk av sengeleie ved ulike tilstander. Sykepleiefaglig forskning og fokus har imidlertid bidratt til en økende erkjennelse av at andre spørsmål og metodiske tilnærminger, spesielt kvalitativ forskning, kan bidra til bedre forståelse og praksis. For eksempel har kvalitativ forskning bidratt til at man i dag bedre forstår hvordan det oppleves å få og leve med en alvorlig kreftsykdom, og slik forskning har bidratt til forbedring av helsetjenesten. Betydningen av kvalitativ forskning illustreres 


\section{Tabell 1: En rangert oversikt over hvilke studier som egner seg best til å svare på effektspørsmål www.cebm.net}

\begin{tabular}{|c|c|}
\hline 1a & SR (with homogeneity*) of RCTs \\
\hline 1b & Individual RCT (with narrow Confidence Interval ) \\
\hline 1c & All or none§ \\
\hline 2a & SR (with homogeneity*) of cohort studies \\
\hline 2b & Individual cohort study (including low quality RCT; e.g., <80\% follow-up) \\
\hline 2c & "Outcomes" Research; Ecological studies \\
\hline 3a & SR (with homogeneity*) of case-control studies \\
\hline 3b & Individual Case-Control Study \\
\hline 4 & Case-series (and poor quality cohort and case-control studies§§) \\
\hline 5 & $\begin{array}{l}\text { Expert opinion without explicit critical appraisal, or based on physiology, } \\
\text { bench research or "first principles" }\end{array}$ \\
\hline
\end{tabular}

også ved at cirka en fjerdedel av alle sammendragene som er publisert $\mathrm{i}$ tidsskriftet Evidence-Based Nursing er rapportering av studier som har brukt kvalitative metoder. Man er også blitt mer og mer opptatt av å utvikle gode metoder for å syntetisere kvalitativ forskning for å kunne utvikle ny kumulativ kunnskap (29).

Cochrane Collaboration og Nasjonalt kunnskapssenter for helsetjenesten har begrenset sine kunnskapsoppsummeringer til primært å dekke effektspørsmål. Randomiserte kontrollerte studier (RCT) representerer den mest robuste fremgangsmåten for å vurdere effekten av et tiltak, det være seg forebygging, behandling, rehabilitering eller organisering av tjenester. Dette har nok vært medvirkende til at RCT-studier er blitt fremhevet som gullstandard innen kunnskapsbasert praksis. Alle effektspørsmål kan imidlertid ikke besvares av slike studier. Vi har flere eksempler på at RCTer kan være både uetiske, upraktiske eller uforsvarlige å gjennomføre (30).

Gjennom et eksempel vil vi illustrere et effektspørsmål besvart med ulike metodiske tilnærminger og vise grunnen til at man innen denne tradisjonen er enige om at de kan rangeres i et hierarki (tabell1).

\section{Eksempel}

Et foreldrepar med barn med kolikk oppsøker helsestasjonen og ber helsesøster om råd. Foreldrene spør om hun vil anbefale å gå til kiropraktor for plagene. Her er de tre alternative kildene helsesøsteren vet om og kan basere informasjonen sin på:

- Kunnskap på nivå 5 (tabell 1): på et seminar har helsesøsteren hørt en kjent kiropraktor snakke varmt om sin behandling av barn med kolikk. Kiropraktoren har meget god erfaring med dette og har mange overbevisende eksempler.

- Kunnskap på nivå 2b (tabell 1). Hun har lest en studie der effekt av kiropraktorbehandling på kolikk er systematisk målt ved at plager før og etter behandling er registrert hos alle barn gjennom tre måneder. Denne studien viser at 70 prosent av barna har tydelig reduksjon av plager etter behandlingen.

- Kunnskap på nivå 1b (tabell 1). Hun har også lest en studie som har tilfeldig fordelt barn med kolikk til to grupper. Den ene gruppen har fått kiropraktorbehandling og i den andre gruppen ble barna bare holdt av en pleier i like lang tid som behandlingen varte. Foreldre visste ikke om barnet hadde fått kiropraktorbehandling eller ei. Resultatene viste at de som fikk kiropraktorbehandling hadde betydelig reduksjon i plager fra kolikk. Men studien viste også at barna som bare ble holdt hadde like stor forbedring (31). Denne studien som er utført i Norge, viser altså at kiropraktorbehandlingen ikke hadde bedre effekt enn ingen behandling.

En dyktig helsesøster må kunne vurdere hvilke av disse kildene hun primært vil støtte seg til i sin informasjon og rådgivning. Hun bør vite at med erfaring alene som veiviser kan man se effekt av tiltak som ikke er reelle, og at før- og ettermålin- ger også er beheftet med feilkilder $(32,33)$. Styrken ved en RCT er at man sammenligner utfallet i to grupper som er så like som mulig (på grunn av den tilfeldige fordelingen), bortsett fra tiltaket som gis. Randomiseringen sikrer også at andre faktorer som kan påvirke utfallet blir likt fordelt i de to gruppene. Dermed kan man i etterkant tilskrive en eventuell forskjell i utfallet, det tiltaket som er studert, i dette tilfellet behandling av kiropraktor. Hvis vi med enda større sikkerhet skal si at tiltaket virker på utfallet vi er interessert i, bør flere gode studier vise det samme, og helst bør studiene være vurdert og sammenstilt i en god systematisk oversikt (kunnskap på nivå $1 \mathrm{a})$.

«Evidensbevegelsen» er blitt oppfattet som om den fremhever en type kunnskap som viktigere enn andre, og at RCT er gullstandard. Vi har utallige ganger presisert at RCT ikke passer til å besvare alle typer spørsmål og at hierarkiet som vi også her har forsøkt å beskrive, handler om effektspørsmål. Vi, og også andre, se for eksempel www. cebm.net, jobber med å utvikle og formidle «hierarkier» også innenfor andre typer spørsmål.

Økningen av RCT innen helsefagene, der man studerer effekt av ikke-farmakologiske tiltak, slikt som trening, gruppeveiledning, ernæring med mere, viser at mange slike tiltak har minst like god effekt som medikamentell behandling, og dessuten mindre bivirkninger. Dette aktualiserer vår plikt som helsearbeider til å sørge for at denne forskningen kommer pasienten til gode. 


\section{Vi jobber for å gi pasienter, sykepleiere og andre helseprofesjoner mer makt og innflytelse.}

\section{Fra Kunnskapsbasert praksis til «Evidence-informed patient choice»} Kunnskapsbasert praksis har bidratt til at forskningsbasert kunnskap er blitt lettere tilgjengelig og forståelig for utøvende helsepersonell, og til at kunnskapen kan understøtte beslutninger. Internasjonalt snakker man mer og mer om Evidence-Informed Decisions i stedet for Evidens-Based Practice. Å bruke dette begrepet tydeliggjør at forskningsbasert kunnskap skal understøtte og informere praksis, men at praksis ikke bør baseres på denne kilden alene. På norsk oversettes «Evidence-Informed Decisions» ofte til «velinformerte beslutninger».

«Make everything open to everyone» er et prinsipp vi jobber for innen kunnskapsbasert praksis, og dette prinsippet har bidratt til at helseinformasjon er blitt lettere tilgjengelig både for helsepersonell og for brukere av helsetjenesten. Vi og mange andre jobber med å videreutvikle konseptet som internasjonalt kalles «evidence-informed patient choice» ved å involvere pasienter og pasientforeninger i Norge, og ved å utvikle kunnskapsbasert pasientinformasjon. «Evidence-informed patient choice» kombinerer prinsippene fra kunnskapsbasert praksis og pasientsentrerte helsetjenester. Vårt mål er at helsetjenestens virkemidler og forskningsaktivitet i større grad skal påvirkes av brukerne av tjenestene. Dette vil også etterspørre mer helsefaglig forskning slik noen studier allerede har vist (34).

Etter vår mening er kunnskapsbasert praksis egnet for de faglige bevisste og for fagutøvere som ikke er villige til å underkaste seg. Vi jobber for å gi pasienter, sykepleiere og andre helseprofesjoner mer makt og innflytelse, og vi hevder at ved å sette flere i stand til å etterspørre, vurdere og bruke forskningsbasert kunnskap, flyttes makt nedover i hierarkiet. Kanskje det er dette som provoserer noen akademikere?

\section{LITTERATUR}

1. McGlynn EA, Asch SM, Adams J, Keesey J, Hicks J, DeCristofaro A, Kerr EA. The quality of health care delivered to adults in the United States. N Engl J Med 2003;348:2681-83.

2. Grol R. Improving the quality of medical care: building bridges among professional pride, payer profit, and patient satisfaction. JAMA 2001;286:2578-85 3. Hjort PE. Uheldige hendelser i helsetjenesten -en lære-, tenke- og faktabok. Gyldendal Norsk Forlag AS 2007.

4. Herbert R, Jamtvedt G, Mead J, Hagen KB. Practical evidence-based physiotherapy. London: Elsevier 2005

5. Jamtvedt G, Hagen KB, Bjørndal A Kunnskapsbasert fysioterapi - Metoder og arbeidsmåter. Gyldendal Akademisk 2003.

6. Bennett S, Tooth L, McKenna K et al. Perceptions of evidence-based practice: A survey of Australian Occupational Therapists. Australian Occupational Therapy Journal 2003;50:13-22.

7. DiCenso A, Guyatt G, Ciliska D.

Evidence-based nursing, A guide to clinical practice. Elsevier Mosby 2005.

8. Nortvedt MW, Jamtvedt G, Graverholt B, Reinar LM. A arbeide og undervise kunnskapsbasert -en arbeidsbok for sykepleiere. NSF Oslo 2007.

9. Ekeland TJ. Evidensbasert praksis. Tidsskrift for Norsk Psykologforening 2008;45: 406-407.
10. Martinsen K. Samtalen, skjønnet og evidensen. Akribe 2005.

11. Ekeli BV. Evidensbasert praksis. Snublestein i arbeidet for bedre kvalitet i helsetjenesten? Eureka 2/2002, Høgskolen i Troms $\varnothing$.

12. Wågø Aas R. ÆEresforeleser ved fagkongressen i Bergen 2009. Vi trenger en opprydning i ergoterapifaget. Intervjuet av Eide, Lena Christina. Ergoterapeuten 2008;11:4-6.

13. Hofstad E. Frykter gammeldags praksis. Sykepleien 2008; 9: 66 .

14. Hofstad E. Evidensialismen - en totalitær ideologi. Sykepleien 2008; 9: 64-65.

15. Heggen K, et al. Dekonstruktiv lesing. Sykepleien Forskning 2009;

$1: 28-33$

16. Bjørndal A, Flottorp S, Klovning A. Medisinsk kunnskapshåndtering. Gyldendal Akademisk 2000.

17. Bennett S, Bennett JW. The process of evidence-based practice in occupational therapy: Informing clinical decisions. Australian Occupational Therapy Journal 2000;47:171-180.

18. Gray JAM. Best current evidence strategy. Consultation paper. Oxford: Connecting for Health, NHS, 2006.

19. Kirkevold K. Vitenskap for praksis? Ad Notam Gyldendal1996.

20. Bridges PH, Bierema LL, Valentine T. The propensity to adopt evidence- based practice among physical therapists.

BMC Health Serv Res 2007;7:103.

21. Metcalfe C, Lewin R, Wisher S. Barriers to implementing the evidence base in four NHS therapies. Physiotherapy 2001 87:441-443.

22. Upton D, Upton P. Knowledge and use of evidence-based practice by allied health and health science professionals in the United Kingdom. J Allied Health 2006;35:127-133.

23. Grol R, Wensing M. What drives change? Barriers to and incentives for achieving evidence-based practice. Med J Aust 2004;180:57-60.

24. Grimshaw JM, Shirran L, Thomas R, Mowatt G, Fraser C, Bero L et al. Changing provider behaviour: an overview of systematic reviews of interventions. Med Care 2001;39:II2-45.

25. Wensing M, Wollersheim H, Grol R. Organizational interventions to implement improvements in patient care: a structured review of reviews. Implement Sci 2006; 1:2.

26. Grol R, Grimshaw J. From best evidence to best practice: effective implementation of change in patients' care. Lancet 2003;362:1225-30.

27. van der Wees PJ, Jamtvedt G, Rebbeck T, de Bie RA, Dekker J, Hendriks

EJ. Multifaceted strategies may increase implementation of physiotherapy clinical guidelines: a systematic review. Aust J Physiother 2008;54:233-41.

28. Newman M, Thompson C, Roberts AP. Helping practitioners understand the contribution of qualitative research to evidence-based practice. Evid Based Nurs 2006;9:4-7

29. Flemming $\mathrm{K}$. The synthesis of qualitative research and evidence-based nursing. Evid Based Nurs 2007;10:68-71. 30. Black N. Why we need observational studies to evaluate the effectiveness of health care. BMJ 1996;312:1215-8.

31. E Olafsdottir, S Forshei, G Fluge and T Markestad. Randomised controlled tria of infantile colic treated with chiropractic spinal manipulation. Arch Dis Child 2001;84:138-141.

32. Polit FP, Beck CT. Essentials of Nursing Research -Methods, Appraisal, and Utilization. London Lippincott Williams and Wilkins (six edition) 2006.

33. Guyatt G, Rennie D, (editors). Users' Guides to the Medical Literature: A Manual for Evidence-Based Clinical Practice. Chicago: American Medical Association, 2008.

34. Tallon D, Chard J, Dieppe P. Exploring the priorities of patients with osteoarthritis of the knee. Arthritis Care Res 2000;13:312-19.

35. Jamtvedt G. Hva er kunnskapsbasert praksis? [online 01.01.2007] Nasjonalt kunnskapssenter for helsetjenesten. 